\title{
Desafios para um novo milênio
}

SÉRGIO MASCARENHAS

Dedico esta modesta contribuição ao grande pensador

A crise atual

$\mathrm{D}$ ILEMA, no dicionário Aurélio, é escolha difícil entre duas alternativas conflitantes. No caso do Brasil, um sistema complexo no sentido moderno da teoria da complexidade (1), o que temos seria um "multilema", muitas alternativas. Na realidade o maior dos problemas é justamente a simultaneidade dos nossos problemas no tempo e no espaço. Entretanto, num sistema complexo, nem todas as variáveis têm igual importância, existe uma hierarquia que nos permite, procurar as chamadas "variáveis de controle". Esta análise, que nos pode tirar da inação, é que leva à esperança de um possível planejamento estratégico para sistemas complexos como os sociais. Historicamente, para países do chamado Terceiro Mundo, em particular na América Latina, um dos primeiros planejamentos estratégicos foi montado na CEPAL, criada pelos gênios políticos de Raul Prebisch e Celso Furtado. Em nível de política científica e tecnológica o Prêmio Nobel Abdus Salam, com quem tive a honra de trabalhar por mais de uma década (2), propôs um quadro de ações para o Terceiro Mundo no seu livro Ideals and realities. Hoje, outro brasileiro, Rubens Ricupero, tenta estruturar na UNCTAD, aliás também proposta e criada por Prebisch, um possível modelo de planejamento para controle de estruturas econômico-financeiras em nível global. Ricupero tem produzido, do seu posto de observação internacional privilegiado, as argutas análises da conjuntura mundial (3).

Nesta época de descrença do Estado e de organismos de planejamento pode parecer ingênuo, e até uma perda de tempo, tratar desses assuntos. Estou, entretanto convencido que há outras alternativas, que não estamos no fim da história, que podemos construí-las. A falta de vontade cooperativa social é a grande patologia deste fim de milênio, que esconde um paradigma novo e simples: podemos começar a cooperar no estabelecimento de uma nova vontade mundial. Por isto me animo a expressar minhas idéias, vindas de experiência - nacional e internacional - de 50 anos no campo da educa- 
ção, da pesquisa científica e do desenvolvimento tecnológico. Reconheço ter experiências limitadas em políticas públicas, a não ser nas áreas citadas. Mas como educação, ciência e desenvolvimento tecnológico passaram a ser variáveis de controle para a análise e o planejamento do desenvolvimento social, anima-me a intuição, se não o convencimento estritamente racional e empírico, de que minhas observações possam ter alguma valia.

Começamos por reconhecer que o planejamento estratégico, que poderá levar a políticas públicas relativas a cenários propostos (o sentido do absoluto não subsiste em planejamento estratégico), começa por análises e estudos dos próprios sistemas. Para sair deste círculo vicioso considerarei que os recentes dados do PNUD (1999) sobre a América Latina podem ser tomados como pontos de partida razoáveis. Menciono e associo-me aqui ao arcabouço montado por Celso Furtado na sua recente obra (4). Acompanho pois Furtado, que propõe ações em três frentes:

\section{Reversão do processo de concentração patrimonial e de rendas}

Segundo o autor, tal processo "está na raiz das malformações sociais" do Brasil. Ressalta ainda que a solução desses problemas é muito mais de ordem política que econômica, lembrando as observações do recente prêmio Nobel Amartya Sen sobre o "enfoque da habilitação". As grandes massas excluídas não são habilitadas pelas elites do poder para a terra, a educação (e, portanto trabalho) e a moradia. Isto leva a situações de descalabro da violência, da criminalidade e talvez a uma situação de agravamento e insolubilidade de nossos problemas. Esta situação é muito semelhante à destruição ocorrida no nosso meio-ambiente, levando em alguns casos ao desaparecimento de nossa fauna, flora, solos, águas. Por falta de vontade política e de objetivos mais concretos advindos dessa condição e correspondente falta de visão dos graves problemas que nos atingem, somos levados à destruição agora do ecossistema-social.

O que paralisa nossa vontade política? A inexistência de grandes lideranças políticas e sociais logo consumidas ou degradadas pelos próprios problemas? Os fatores internacionais da recolonização pela globalização financeira e tecnológica? A corrupção sistêmica e sistemática, embutida na desordem e na vertiginosa movimentação dos trilhões de dólares que vagam eletronicamente sobre as nações, irrigando ao mesmo tempo a concentração de recursos no sistema financeiro, as drogas e a mídia serviçal? Com a destruição da utopia socialista houve como que um cataclisma, uma fragorosa destruição de diques que levaram ao vale-tudo da especulação e da selvageria financeira associados à violência e ao desemprego. 


\section{Atraso no indice de desenvolvimento bumano e social como utilizado pelas Nações Unidas para a avaliação das diferentes sociedades}

Este índice aponta o Brasil como excepcionalmente atrasado $\left(74^{\circ} \mathrm{lu}\right.$ gar) em relação à sua renda per capita. Furtado chega a afirmar que "a miséria de grande parte do povo brasileiro é a contrapartida do hiperconsumo praticado por uma pequena minoria em termos relativos".

\section{Inadequação no processo de inserção na globalização}

Com a transferência de todas as principais capacidades de controle ou manobra das crises de ataques especulativos do capital internacional ou das empresas multinacionais ou transnacionais, inclusive perda de importantes mercados internos pela privatização açodada e muitas vezes inconseqüente de empresas nacionais para pagamento dos serviços de dívidas ou obtenção de recursos, algumas vezes com fins puramente eleitoreiros. O grande perigo é agora a completa dolarização da economia que seria (ou será?) a perda completa de autonomia como Estado, nação e povo. As pressões para tanto são enormes e já começam a surtir efeito em economias mais frágeis. O tempo e o futuro dirão dessa grande ameaça, talvez a maior e mais devastadora de todas, à qual não sucumbiram ainda apenas a China e uns poucos países do mundo.

\section{Um possível glorioso amanhecer? \\ Educação, ciência e tecnologia: \\ desafios, possibilidades e oportunidades}

Com esse balizamento geral estruturado por Furtado, passo às minhas considerações mais diretas com o que considero ser uma proposta de alternativas nascida das minhas experiências como pesquisador científico, consultor na área de desenvolvimento tecnológico e professor.

A nossa civilização vive um momento de excepcionais possibilidades. A globalização das comunicações iconizada pela web, o enorme impulso das pesquisas básicas e tecnológicas, as novas tecnologias educacionais rompendo barreiras de povos e culturas, a era espacial que já penetra nas nossas estruturas sociais e culturais, sobretudo pelas telecomunicações, podem nos oferecer em contraposição ao título de "longo amanhecer", escolhido por Furtado, um "novo amanhecer" caso saibamos entender e aproveitar todas estas novas oportunidades. Reconhecemos que a competição é muito acirrada e que temos difíceis condições legadas pelo "longo amanhecer". Por outro lado, temos alguns argumentos e fatos que nos permitem acreditar em 
desempenhos mais favoráveis e mesmo contar com exemplos internacionais, verdadeiros laboratórios (5) nos quais poderemos recolher valiosas informações. O essencial será encontrar as forças, vontades e lideranças políticas, empresariais, científicas e culturais que permitam a realização de tais esforços contra os obstáculos e impedimentos naturais, que são obviamente os interesses conflitantes das atuais forças dominadoras. Esse é o grande dilema desta fase histórica que Helio Jaguaribe denomina a da Pax Americana (6).

\section{Uma proposta: a guerrilha do desenvolvimento}

Para ir diretamente ao cerne da questão: nesta grande guerra pelo desenvolvimento em plena recolonização financeira e tecnológica da Pax Americana, uma das poucas estratégias possíveis não é a da guerra global ou enfrentamentos radicais, mas a de verdadeiras "guerrilhas estratégicas". Estas são realizadas mediante políticas setoriais regionalizadas, com ilhas e núcleos de excelência. Estas ilhas e núcleos, após estruturados, poderão expandir-se gradualmente e agregar-se mais amplamente para cenários e opções mais ambiciosas. O enfrentamento Mercosul-Alca ilustra o policiamento estratégico ao qual estamos submetidos na Pax Americana. E, indiretamente, portanto, a validade de tal política regionalista.

Esta é uma diferença essencial com os grandes planejamentos centrais que induzem a gigantescas dificuldades. Isto ocorreu no caso da ex-União Soviética. Sem ser uma defesa radical do small is beautiful, proponho a otimização e adaptabilidade de escalas para evitar disfunções. Creio mesmo que a presente onda de grandes fusões empresariais poderá levar a disfunções graves e talvez letais de muitos conglomerados e, conseqüentemente, a maior desemprego e talvez a violenta crise, como a de 1928.

$\mathrm{Na}$ área da pesquisa e do desenvolvimento científico e tecnológico fomos testemunhas de tal processo involutivo em importantes laboratórios nos Estados Unidos e na Europa como os da IBM, RCA, Westinghouse Research Labs., Bell Labs., entre outros. Embora reconheçamos que existem exemplos de sucesso de grandes laboratórios como o Centre Européen de Recherches Nucleaires (CERN), o National Aerounatics and Space Administration (NASA), o National Institutes of Health (NIH) e outros, mas sempre para objetivos mais específicos. Pelo contrário, redes e não os conglomerados ganham em eficiência e funcionalidade, aumentando a inovação e competitividade, ao mesmo tempo em que favorecem a cooperatividade. O conceito de rede é hoje um conceito vitorioso em muitas áreas da ciência, tecnologia, ciências sociais e humanidades. A Embrapa (Empresa Brasileira de Pesquisas Agropecuárias), por exemplo, uma das instituições de maior sucesso no Bra- 
sil e na América Latina, funciona como rede de centros e laboratórios. Acho, entretanto, que devemos associar ao conceito de redes o de centros ou núcleos emergentes induzidos por núcleos de excelência. Esses centros emergentes são os que catalisam o desenvolvimento mais amplo e formam a textura capilar que dá sustentabilidade aos sistemas. Esta rede pode evoluir e criar uma nova vontade política em nível nacional e até mesmo internacional.

Organizados em torno de planejamentos estratégicos regionais setorizados, nascidos de uma estruturação cooperativa em redes, poderíamos obter bons resultados nos gargalos básicos de nosso desenvolvimento: educação, pesquisa e desenvolvimento científico e tecnológico, políticas públicas nas áreas sociais de saúde, moradia, emprego e terra, desenvolvimento econômico, meio ambiente, cultura, cidadania, demografia, entre tantos outros.

Creio, portanto, que o que se requer é uma mudança estrutural gradual para passar de planejamentos centrais a um novo sistema de planejamento estratégico mais descentralizado e regionalizado com grande ênfase em centros e programas emergentes regionais que permitem, e até induzem, o aparecimento de novas lideranças e novas visões mais dinâmicas, pluralistas de nossa sociedade. Com isso incorporaríamos o ingrediente mais importante para nosso desenvolvimento: novas lideranças a partir da população mais jovem, ampliando o espaço de nossa governança democrática para vários setores e regiões do Brasil.

Nada como exemplos e casos reais para se avaliar tais sugestões. Tivemos ocasião de acompanhar e, em certos casos participar, de algumas iniciativas que, dentro desta visão, tiveram sucesso, entre as quais podemos citar:

- implantação e nucleação de um centro regional de física no Nordeste, em Recife sob a liderança de Sérgio Machado Rezende e sua equipe, que mudou qualitativa e quantitativamente as perspectivas científicas e tecnológicas da região incluindo novas políticas públicas como a criação da Fundação para o Amparo da Ciência e Tecnologia e a própria Secretaria de Ciência Tecnologia e Meio Ambiente do Estado de Pernambuco. Este modelo vitorioso mostra que há grandes possibilidades de ações semelhantes no setor de desenvolvimento científico e tecnológico até no Nordeste e em outras regiões mais desfavorecidas.

- Implantação, nucleação e desenvolvimento da Engenharia de Materiais no Brasil, na Universidade Federal de São Carlos a partir da USP-São Carlos, que mudou o perfil da engenharia nacional com importantes reflexos econômicos e tecnológicos incluindo novos recursos humanos de alto nível no setor. Formaram-se mais de mil engenheiros e centenas de mestres e doutores desde a fundação do curso em 1970 (7). 
- Implantação e nucleação do Centro Nacional de Pesquisas e Desenvolvimento de Instrumentação Agropecuária da Embrapa em São Carlos, que introduziu um novo estilo de ação de pesquisa tecnológica em Agropecuária, modelo inclusive para a América Latina. Também a partir da USP-São Carlos e com o apoio da visão e ousadia de Eliseu Roberto de Andrade Alves, um dos pioneiros da fundação da Embrapa, bem como dos esforços de excepcionais pesquisadores como Silvio Crestana e Paulo Cruvinel, seus chefes sucessivos.

- Implantação e nucleação dos Institutos de Física e Química da USP em São Carlos, que com os outros Institutos da USP e da UFSCAR catalisaram a formação do pólo científico e tecnológico de São Carlos e induziram a criação de vários outros centros, empresas e indústrias de alta tecnologia na região e no país.

- Importante exemplo de sucesso é a Fapesp, que por seus vários programas descentralizados forma eficientes redes de pesquisa e desenvolvimento científico e tecnológico. A Fapesp, mediante gestões ousadas como nos projetos de genômica, ilustra como a formação de redes de pesquisa ou projetos temáticos cooperativos pode amplificar a influência sócio-econômica da ciência e tecnologia. Essas iniciativas foram devidas a excepcionais lideranças científicas: Oscar Sala, Flávio Fava de Moraes e José Fernando Perez.

Gostaria, nesse ponto, de fazer uma observação que julgo relevante para nossos dilemas e desafios: a necessidade da figura do que denomino "empreendedor de ciência-tecnologia e de educação". Note-se que cuidadosamente me referi não ao cientista-empresário nem ao empresário-cientista, nem ao empresário somente, mas ao empreendedor da ciência e da educação. Em outras palavras, àquelas lideranças, públicas ou privadas, com capacidade organizativa e liderança pró-ativa que permitem avanços rápidos e diferenciados na sociedade, através de inovação, ousadia de objetivos e, sobretudo, formação de novas lideranças. Dentre os falecidos, tenho em mente perfis como os de Anísio Teixeira, Paulo Freire e Darcy Ribeiro, na Educação, e Oswaldo Cruz, Carlos Chagas, Álvaro Alberto, Joaquim da Costa Ribeiro e Carlos Chagas Filho, na Ciência. Pessoalmente tive a fortuna de trabalhar com Anísio Teixeira e Costa Ribeiro, acompanhando de perto as suas lutas. No âmbito internacional do Terceiro Mundo, cito a figura de Abdus Salam, Prêmio Nobel de física, oriundo do Paquistão e com quem tive também a honra de trabalhar no hoje denominado Abdus Salam International Center for Theoretical Physics, em Trieste, verdadeiro estadista da ciência mundial e grande empreendedor da ciência e educação, no sentido ao qual me referi (8). Não posso deixar de citar mais uma vez Raul Prebisch, da Argentina, econo- 
mista e visionário excepcional, criador da CEPAL e de outros organismos internacionais. Estes nomes são citados a fim de não se julgar que, apesar de imensas dificuldades, não tenhamos produzido líderes exemplares que nos sirvam de paradigmas.

Estas visão e ênfase em áreas da educação, ciência e tecnologia, lideranças e pessoas, podem parecer menos práticas que discussões e sofisticadas análises mais globais, porém foi o caminho vitorioso de todos os países centrais ou de desenvolvimento acelerado recente, sobretudo na construção das riquezas e das culturas que os propulsionaram. No caso do Brasil a situação é mais grave, pois requer mudanças culturais mais profundas, por exemplo, com relação à participação das novas gerações como empreendedores públicos e privados, armados com uma visão da importância fundamental da ciência e tecnologia. Infelizmente, mesmo os nossos modernos administradores, com raras exceções, têm conhecimento apenas superficial de ciência, tecnologia e educação. E tudo isso se passa na presença e companhia de outra geração ainda congelada em uma cultura no máximo da era fordista. Esta geração intermediária controla, às vezes com arrogância, as grandes decisões de políticas públicas e privadas no país ligadas ao desenvolvimento da ciência, tecnologia e educação.

A falta de entendimento e vocabulário entre essas gerações impede a existência de uma verdadeira "linguagem" em que expressarmos a vontade nacional e na qual educarmos as novas gerações subseqüentes. Este grave hiato é uma das patologias mais sérias de que sofremos no Brasil e motivo também de graves descontinuidades de apoio ao nosso desenvolvimento na era do conhecimento. Recentemente José Galizia Tundisi, um dos maiores cientistas brasileiros na área do meio ambiente, viu interrompidos seus esforços à frente do Conselho Nacional do Desenvolvimento Científico e Tecnológico, com graves prejuízos para o país.

A crise à qual se refere Amartya Sem passa também por essa falta de "habilitação" política na área de ciência e tecnologia e do conhecimento atualizado, engendrando um grau de analfabetismo científico cruel e danoso. Para mudar este quadro, que é cultural e herdado de séculos de dependência e ausência de uma influência maior de ciência e tecnologia (9), será imprescindível uma revolução educacional com bases mais adequadas à era do conhecimento sem desprezarmos, é claro, o que de bom existe na nossa base cultural multi-racial clássica como literatura, música, artes e esportes. Lembro-me de Anísio Teixeira dizendo-me, com aquele brilho visionário nos olhos: "precisamos encher o Maracanã para a educação científica!" Fui com ele à sua Bahia para, a seu pedido, dar curso de ensino de ciências para professoras primárias. Estamos ainda lutando por estas mudanças e mesmo as básicas, como demons- 
tra inequivocamente Alfredo Bosi (10), ainda estão por ser feitas. Em artigo no qual descreve o que encontrou como panorama da situação financeira dos professores e professoras do primeiro grau no Brasil: hora-aula na faixa dos R\$ 1,5 a 3 em todos os estados brasileiros, inclusive São Paulo!

\section{Conclusões e propostas}

Como se pode inferir do que proponho, as variáveis fundamentais para serem atendidas são pois:

- desenvolvimento científico, tecnológico e educacional mediante programas regionais visando à formação de centros emergentes nestes setores, por meio de metas e vocações setoriais e de integração interdisciplinar. Na área científica e tecnológica, a implantação mais decidida de pólos de desenvolvimento com forte acoplamento universidadeempresa-ensino médio e profissionalizante. Criação, nesses pólos, de centros de ciências e tecnologias educacionais, com respectivos centros de produção de multimídia e ensino a distância associados. Note-se que associamos ciências da educação a tecnologias educacionais, sem o que não se atingirá o necessário grau de qualidade do processo ensinoaprendizagem e se obterá apenas soft-hard-ware sem brain-human-ware. Devemos reconhecer que o Ministério de Educação atual tem buscado encetar esforços nestas linhas implementando vários programas especiais.

- Um esforço complementar na área da cultura e educação para incluir ciência e tecnologia como novos elementos necessários à formação de uma nova vontade política e visão de mundo na nossa mocidade. Para tanto é urgente a criação de uma rede de centros e museus de ciências em todo o país, sustentada por verbas permanentes públicas e privadas, sob forma de Fundação Nacional de Centros e Museus de Ciências. Destas rede e Fundação, poderão surgir uma nova cultura e uma nova cidadania mais adequadas à nova era do conhecimento que estamos iniciando. Tais problemas foram expostos em livro publicado recentemente (11) e que há muito vêm sendo focalizados por Crodowaldo Pavan, José Reis, Isaias Raw, Ernesto e Amélia Hamburger, Shigueo Watanabe, Yvonne P. Mascarenhas, Dietrich Schiel, Antonio Teixeira Jr., Julieta Ormastroni, nós próprios e muitos outros sob seus diferentes ângulos e visões.

- Ciência e tecnologia sem complementação dos ricos traços humanísticos de nossa cultura multi-racial e tradições artísticas, literárias, musicais e esportivas não bastam para atingir os objetivos de formar uma nova plataforma de valores e cidadãos para o lançamento desse "Novo Amanhecer". 
Nada melhor que a figura de Janus - o deus bifronte romano - mirando o passado e suas tradições, e o futuro e suas potencialidades, para iconizar estas idéias e propostas.

Notas

1 H.M. Nunzeisweig (coord.), Sistemas Complexos, Rio de Janeiro, Ed. UFRJ.

2 Abdus Salam, Ideals and realities, Trieste, Italy, ed. ICTP, 1990.

3 Ver de Rubens Ricupero, por exemplo, Ponto ótimo da crise, Ed. Revan, 1998

4 Celso Furtado, O longo amanhecer, Rio de Janeiro, Paz e Terra, 1999.

5 Vide artigo de Paul Singer, publicado na revista do IEA-USP, Estudos Avançados, n.38, p.247.

6 Hélio Jaguaribe, Estudos Avançados, n. 39, p. 215.

7 Vide Trinta anos de engenharia de materiais no Brasil, de autoria de José Roberto Gonçalves, $\mathrm{PhD}$ em Ciência de Materiais e professor adjunto do DEMA-UFSCar, 24 janeiro 1999.

8 Sérgio Mascarenhas, Ideals and realities: working with Abdus Salam, in: A.M. Hamende (ed.), Tribute to Abdus Salam, 1997.

9 Vide Sérgio Mascarenhas, Celso Furtado, Hélio Jaguaribe, Miguel Real e José Reis, Raizes e Perspectivas do Brasil, Campinas, Ed. Unicamp, 1985, para uma análise feita por José Reis e Sérgio Mascarenhas.

10 Alfredo Bosi, O ponto cego da Educação, Folha de S. Paulo, 1997.

11 Silvério Crestana, Miriam Goldman de Castro \& Gilson R.M. Pereira (coords.) Centros e Museus de Ciências: visões e experiências, São Paulo, Saraiva, 1998.

Sérgio Mascarenhas, físico, é coordenador do Instituto de Estudos Avançados da USP em São Carlos, diretor do Programa Internacional de Estudos e Projetos para a América Latina e professor emérito do Instituto de Física de São Carlos-USP.

O autor agradece a Yvonne Primerano Mascarenhas, Yvone Maria Mascarenhas Hornos, Oswaldo Baffa, Sérgio e Clotilde Ferreira e Marcos Mucheroni pela leitura do manuscrito. 